\title{
Epidemiologia, sinais clínicos e distribuição das lesões encefálicas em bovinos afetados por meningoencefalite por herpesvírus bovino- $5^{1}$
}

\author{
Daniel R. Rissi ${ }^{2}$, Fabiano N. Oliveira ${ }^{3}$, Raquel R. Rech ${ }^{2}$, Felipe Pierezan ${ }^{4}$, \\ Ricardo A.A. Lemos $^{5}$ e Claudio S.L. Barros ${ }^{6 *}$
}

\begin{abstract}
Rissi D.R., Oliveira F.N., Rech R.R., Pierezan F., Lemos R.A.A. \& Barros C.S.L. 2006. [Epidemiology, clinical signs and distribution of the encephalic lesions in cattle affected by meningoencephalitis caused by bovine herpesvirus-5.] Epidemiologia, sinais clínicos e distribuição das lesões encefálicas em bovinos afetados por meningoencefalite por herpesvírus bovino-5. Pesquisa Veterinária Brasileira 26(2):123-132. Departamento de Patologia, Universidade Federal de Santa Maria, 97105-900, Santa Maria, RS, Brazil. E-mail: claudioslbarros@uol.com.br

Seven outbreaks and an isolated case of meningoencephalitis caused by bovine herpesvirus- 5 (BoHV-5) in cattle in Rio Grande do Sul, Brazil, occurring in 2002-2004, are described. From a total population at risk of 1,359 cattle, 54 1-18-month-old calves from both sexes and several breeds were affected and 50 died spontaneously or were euthanatized while moribund. The highest frequency of cases was in recently weaned calves or calves submitted to other stressing factors. General rates of morbidity, mortality and lethality were respectively $3.97,3.67$ and $92.59 \%$. Clinical courses varied from 3-10 days and included depression, nasal and ocular discharge, grinding of teeth, circling, blindness, fever, nistagmus, trembling, anorexia, dysphagia, drooling, incoordination, head pressing, rough hair coat, tachycardia, tachypnea, abdominal pain, melena, falls, recumbency, opisthotonus, convulsions and paddling. Nineteen calves were necropsied. Necropsy findings were characterized by hyperemia of leptomeninges, swollen rostral portions of the telencephalon, and flattening of frontal lobes gyri; frequently in these frontal areas there were segmental brown-yellow discoloration and softening (malacia) of the cortex. In cases with more protracted clinical courses there were extensive swelling, softening and hemorrhaging of the telencephalic frontal lobes. Microscopically, all affected cattle had a necrotizing non-suppurative meningoencephalitis with variable distribution among the 19 cases and among the various telencephalic regions of the same case. The severity of these changes were more marked, in decreasing order of intensity, in the telencephalic frontal cortex, basal ganglia (nuclei), thalamus, brain stem, parietal telencephalic cortex, occipital telencephalic cortex and cerebellum. Perivascular inflammatory infiltrate consisted predominantly of lymphocytes, plasm cells, and less frequently of neutrophils. Additional microscopic findings included variable degrees of gliosis, edema, neuronal necrosis in the telencephalic cortex characterized by shrinking and eosinophilia of perikaria and nuclear picnosis (red neuron); basophilic intranuclear inclusion bodies in astrocytes and neurons ( $21.05 \%$ of the cases); sattelitosis; and neuronophagia. The areas of softening in the cortical substance consisted of necrosis of the neuroctodermal elements with maintenance of mesenchymal structures (vessels and microglia), infiltrate of Gitter cells, and, in more severe cases, extensive hemorrhages. In chronic cases, only vascular structures and a few Gitter cells remained in the cortical area leaving a cavity between white matter and leptomeninges (residual lesion).
\end{abstract}

INDEX TERMS: Bovine herpesvirus-5, BoHV-5, encephalitis, diseases of cattle, viral diseases, neuropathology.

\footnotetext{
${ }^{1}$ Recebido em 19 de dezembro de 2005.

Aceito para publicação em 5 de janeiro de 2006.

Parte da dissertação de mestrado do primeiro autor (Bolsista do CNPq).

${ }^{2}$ Programa de Pós-graduação em Medicina Veterinária, área de concentração em Patologia Veterinária, Centro de Ciências Rurais, Universidade Federal de Santa Maria (UFSM), 97105-900 Santa Maria, RS, Brasil.
}

\footnotetext{
${ }^{3}$ Texas A\&M University. College of Veterinary Medicine, Veterinary Pathobiology (VTPB), College Station, TX 77843-4461, USA.

${ }^{4}$ Bolsista de iniciação científica do PIBIC/UFSM.

${ }^{5}$ Departamento de Medicina Veterinária, Universidade Federal do Mato Grosso do Sul, Cx. Postal 649, 79070-900 Campo Grande, MS, Brasil.

${ }^{6}$ Departamento de Patologia, UFSM, 97105-900, Santa Maria, RS. *Autor para correspondência. E-mail: claudioslbarros@uol.com.br.
} 
RESUMO.- São descritos sete surtos e um caso isolado de meningoencefalite por herpesvírus bovino-5 (BoHV-5) em bovinos no Rio Grande do Sul entre 2002 e 2004. Foram afetados bovinos de 1-18 meses, de diversas raças e ambos os sexos. A maior freqüência foi observada em bovinos recém-desmamados e submetidos a outros fatores de estresse. Nesses surtos, de uma população total sob risco de 1.359 bovinos, 54 foram afetados, quatro se recuperaram e 50 morreram espontaneamente ou foram submetidos à eutanásia quando moribundos. Os índices gerais de morbidade, mortalidade e letalidade foram, respectivamente, de 3,97\%, 3,67\% e 92,59\%. A evolução clínica variou de 3-10 dias e os sinais eram caracterizados por depressão, corrimento nasal ou ocular, ranger de dentes, andar em círculos, cegueira, febre, nistagmo, tremores, anorexia, disfagia, sialorréia, incoordenação, pressão da cabeça contra objetos, pêlos arrepiados, taquicardia, taquipnéia, dor abdominal, melena, quedas, decúbito, opistótono, convulsões e movimentos de pedalagem. Dezenove bezerros foram necropsiados. Achados de necropsia foram caracterizados por hiperemia das leptomeninges, tumefação das porções rostrais do telencéfalo, com achatamento das circunvoluções dos lobos frontais; nessas áreas havia focos marrom-amarelados e amolecidos (malacia). Nos casos de evolução clínica mais longa era observada acentuada tumefação, amolecimento e extensas áreas de hemorragia nos lobos frontais telencefálicos. Microscopicamente, todos os bovinos afetados apresentaram meningoencefalite nãosupurativa e necrosante, que variou quanto à localização e intensidade nos 19 casos examinados e nas seções de encéfalo de um mesmo caso. A intensidade dessas lesões foi mais acentuada, em ordem decrescente, no córtex telencefálico frontal, nos núcleos da base, tálamo, tronco encefálico, córtex parietal, córtex occipital e cerebelo. $O$ infiltrado inflamatório perivascular era constituído predominantemente por linfócitos e plasmócitos e, menos freqüientemente, neutrófilos. Outros achados incluíam variados graus de gliose, edema, necrose neuronal no córtex telencefálico, caracterizada por encarquilhamento e eosinofilia do citoplasma e picnose nuclear (neurônio vermelho), corpúsculos de inclusão basofílicos intranucleares em astrócitos e neurônios ( $21,05 \%$ dos casos), satelitose e neuronofagia. As áreas de amolecimento do parênquima eram caracterizadas por necrose do componente neuroectodérmico e manutenção das estruturas mesenquimais (vasos e micróglia), com infiltrado de células Gitter e, em casos mais graves, áreas de hemorragia. Nos casos crônicos apenas estruturas vasculares e poucas células Gitter permaneciam, formando uma cavidade entre a substância branca e as leptomeninges (lesão residual).

TERMOS DE INDEXAÇÃO: Herpesvírus bovino-5, BoHV-5, encefalite, doenças de bovinos, doenças virais, neuropatologia.

\section{INTRODUÇ̃̃o}

A meningoencefalite por herpesvírus bovino-5 (BoHV-5) é uma doença infecciosa, aguda e altamente fatal, que afeta principalmente bovinos jovens. É caracterizada por sinais clínicos neurológicos corticais associados à meningoencefalite com necrose do córtex telencefálico. A enfermidade é atualmente relatada em vários países, principalmente na América do Sul (Johnston et al.
1962, Dias et al. 1982, Carrillo et al. 1983a,b, Riet-Correa et al. 1989, Weiblen et al. 1989, Salvador et al. 1998, Colodel et al. 2002, Elias et al. 2004).

O objetivo deste trabalho é relatar os aspectos epidemiológicos, sinais clínicos e distribuição das lesões encefálicas de 19 bovinos afetados por meningoencefalite por BoHV-5, visando orientar veterinários de diversas áreas para o reconhecimento da enfermidade e diferenciá-la de outras doenças do sistema nervoso central (SNC) de bovinos no Brasil. Esse estudo faz parte de uma série que vem sendo realizada em nosso laboratório com a finalidade de documentar lesões e doenças do SNC, a fim de facilitar o diagnóstico diferencial das enfermidades ou lesões do SNC nessa espécie, como parte da vigilância da encefalopatia espongiforme bovina (BSE), coordenada pelo Programa Nacional de Controle da Raiva dos Herbívoros e Outras Encefalopatias (PNCRH) do Ministério da Agricultura Pecuária e Abastecimento (MAPA).

\section{MATERIAL E MÉTODOS}

Dados epidemiológicos e clínicos de casos de meningoencefalite por BoHV-5 foram obtidos junto aos proprietários e aos veterinários durante visitas às propriedades ou por ocasião do recebimento do material no Laboratório de Patologia Veterinária (LPV) da Universidade Federal de Santa Maria (UFSM). Foram estudados sete surtos e um caso isolado em oito propriedades rurais do Rio Grande do Sul, e realizadas 19 necropsias em bovinos que morreram espontaneamente da infecção ou que foram submetidos à eutanásia quando moribundos.

Para a caracterização do tipo e intensidade da distribuição das lesões encefálicas, os encéfalos dos bovinos foram coletados inteiros e fixados em formol a $10 \%$, juntamente com o gânglio do nervo trigêmeo (gânglio de Gasser), hipófise e rete mirabile carotídea, e diversos órgãos, incluindo pulmão, fígado, rim e coração. Após fixação, os encéfalos foram seccionados transversalmente em intervalos de $1-2 \mathrm{~cm}$ para exame macroscópico. Foram selecionadas as seguintes seções para exame histológico: 1) bulbo na altura do óbex, 2) cerebelo, 3) ponte com pedúnculos cerebelares, 4) mesencéfalo na altura dos colículos rostrais, 5) tálamo, 6) hipocampo, 7) córtex occipital, 8) córtex sobre o tálamo, e 9) córtex frontal na altura do joelho do corpo caloso e dos núcleos basais (Barros \& Marques 2003). Adicionalmente, foram examinados em monobloco o gânglio de Gasser, hipófise e rete mirabile. Fragmentos de todos os órgãos coletados foram processados rotineiramente para histologia e corados pela técnica de hematoxilinaeosina. Fragmentos de bulbo olfatório, córtex telencefálico frontal e swab nasal foram remetidos a um laboratório de virologia para identificação do agente.

As lesões observadas no encéfalo foram graduadas de 1-3, de acordo com a intensidade. Essa graduação foi feita de acordo com a média de percepção subjetiva de quatro patologistas que examinaram as lâminas. Os seguintes aspectos foram computados para a obtenção da intensidade das lesões: 1) hemorragia, 2) edema da neurópila, 3) tumefação das células endoteliais, 4) infiltrado inflamatório, 5) meningite, 6) gliose focal, 7) gliose difusa, 8) neurônios vermelhos (neurônios com o citoplasma encolhido e eosinofílico e núcleo picnótico), 9) neuronofagia, 10) malacia (necrose do componente neuroectodérmico com manutenção das estruturas mesenquimais e infiltrado de macrófagos tumefeitos e com citoplasma espumoso [células Gitter]), e 11) lesão residual (estruturas vasculares e células Gitter remanescentes, formando uma estrutura cavitária semelhante a um cisto). Cada um dos parâmetros avaliados foi relacionado à 
seção anatômica examinada, com o objetivo de determinar a localização das lesões produzidas pela doença no SNC. Adicionalmente, foram avaliados qualitativamente o tipo de infiltrado inflamatório, a presença de corpúsculos de inclusão intranucleares característicos de herpesvírus e a presença de vasculite.

\section{RESULTADOS}

\section{Epidemiologia}

Um resumo dos dados epidemiológicos dos casos de meningoencefalite por BoHV-5 em bovinos de oito proprieda- realizado com base nos achados epidemiológicos, clínicos e, principalmente, na histopatologia, que foram idênticos aos dos outros surtos deste estudo.

\section{Sinais clínicos}

Os sinais clínicos tiveram evolução de 3-10 dias e foram semelhantes em todos os surtos (Fig.2). Depressão (Fig.3) e corrimento nasal (Fig. 4) foram os achados mais freqüentes. A temperatura retal variou de $40,0-42,5^{\circ} \mathrm{C}$, mas não foi aferida em todos os casos.

Quadro 1. Epidemiologia dos surtos de meningoencefalite por herpesvírus bovino-5

\begin{tabular}{|c|c|c|c|c|c|c|}
\hline Propr $^{\mathrm{a}}$ & Época do ano & $\begin{array}{c}\text { Bovinos } \\
\text { sob risco }\end{array}$ & $\begin{array}{c}\text { Bovinos afetados } \\
(\mathrm{Mb})^{\mathrm{b}}\end{array}$ & $\begin{array}{l}\text { Bovinos mortos } \\
\left(\mathrm{Mt}^{\mathrm{C}} / \mathrm{Lt}^{\mathrm{d}}\right)\end{array}$ & $\begin{array}{l}\text { Duração do } \\
\text { curso clínico }\end{array}$ & $\begin{array}{l}\text { Confirmação } \\
\text { do diagnóstico }\end{array}$ \\
\hline 1 & Janeiro & 300 & $5(1,6 \%)$ & $5(1,6 \% / 100 \%)$ & 4 dias & ICC \\
\hline 2 & Abril & 224 & $1(0,4 \%)$ & $1(0,4 \% / 100 \%)$ & 10 dias & Histopatologia \\
\hline 3 & Julho & 200 & 27 (13,5\%) & 27 (13,5\%/100\%) & Até 10 dias & ICC e IFA ${ }^{f}$ \\
\hline 4 & Fevereiro & 100 & $3(3 \%)$ & $3(3 \% / 100 \%)$ & 7 dias & Histopatologia \\
\hline 5 & Maio & 15 & $3(20 \%)$ & $3(20 \% / 100 \%)$ & 3-4 dias & Histopatologia \\
\hline 6 & Maio & 200 & $7(3,5 \%)$ & $4(2 \% / 57,1 \%)$ & 3-4 dias & Histopatologia \\
\hline 7 & Agosto & 300 & $5(1,6 \%)$ & $4(1,3 \% / 80 \%)$ & 4-10 dias & PCR ${ }^{g}$ \\
\hline \multirow[t]{2}{*}{8} & Outubro & 20 & $3(15 \%)$ & $3(15 \% / 100 \%)$ & 7 dias & Histopatologia \\
\hline & Totais & 1.359 & $54(3,97 \%)$ & $50(3,67 \% / 92,59 \%)$ & & \\
\hline
\end{tabular}

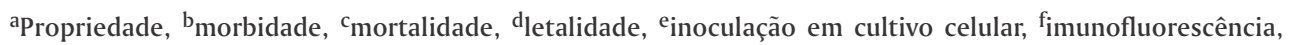
$\mathrm{g}_{\text {reação em cadeia da polimerase. }}$

Quadro 2. Presênça de fatores de estresse e tipo de alimentação dos bovinos envolvidos nos surtos de meningoencefalite por herpesvírus bovino-5

\begin{tabular}{|c|c|c|}
\hline Propr $^{\mathrm{a}}$ & Fatores de estresse & Alimentação \\
\hline 1 & Não identificado & $\begin{array}{l}\text { Pastejo rotativo e concentrado em } \\
\text { cocho comum }\end{array}$ \\
\hline 2 & $\begin{array}{l}\text { Desmame } 30 \text { dias antes do } \\
\text { aparecimento da doença }\end{array}$ & $\begin{array}{l}\text { Pastagem de azevém e feno } \\
\text { e ração em cocho comum }\end{array}$ \\
\hline 3 & $\begin{array}{l}\text { Desmame } 90 \text { dias antes do } \\
\text { aparecimento da doença }\end{array}$ & $\begin{array}{l}\text { Alimentados em cocho comum com } \\
\text { concentrado e pasto verde cortado }\end{array}$ \\
\hline 4 & $\begin{array}{l}\text { Desmame } 60 \text { dias antes do } \\
\text { aparecimento da doença }\end{array}$ & Pastejo em campo nativo \\
\hline 5 & $\begin{array}{l}\text { Desmame } 20 \text { dias antes do } \\
\text { aparecimento da doença }\end{array}$ & Pastagem de aveia cultivada \\
\hline 6 & $\begin{array}{l}\text { Desmame } 120 \text { dias antes do } \\
\text { aparecimento da doença }\end{array}$ & $\begin{array}{l}\text { Pastagem de aveia cultivada e con- } \\
\text { centrado em cocho comum }\end{array}$ \\
\hline 7 & $\begin{array}{l}\text { Desmame } 20 \text { dias antes do } \\
\text { aparecimento da doença }\end{array}$ & Pastagem de aveia cultivada \\
\hline 8 & Afastamento da vaca & $\begin{array}{l}\text { Piquete de campo nativo, leite duas vezes } \\
\text { ao dia e cana cortada em cocho comum }\end{array}$ \\
\hline
\end{tabular}

apropriedade.

des rurais estudadas encontra-se nos Quadros 1 e 2 e Figura 1. Os casos ocorreram entre 2002-2004 em vários municípios do Rio Grande do Sul, onde foram afetados bovinos de 1-18 meses, de diversas raças e ambos os sexos. A maior freqüiência foi observada em bovinos recém-desmamados e submetidos a outros fatores de estresse.

Em 3 surtos (14 bovinos), a confirmação do diagnóstico foi realizada por inoculação em cultivo celular, imunofluorescência e PCR e em 5 surtos não foi enviado material para virologia ou o resultado foi negativo na inoculação em cultivo celular. Nesses casos o diagnóstico de meningoencefalite por herpesvírus foi

\section{Achados de necropsia}

Os achados de necropsia foram consistentes em todos os casos examinados e eram restritos ao encéfalo. Nos encéfalos

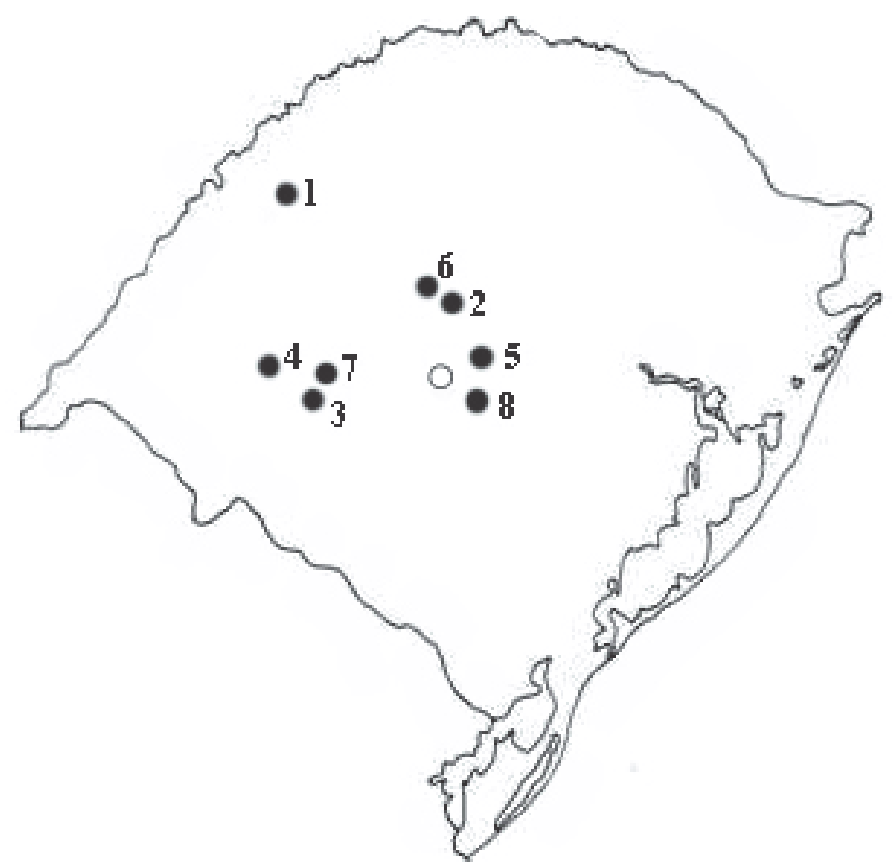

Fig.1. Mapa do Rio Grande do Sul com a localização dos municípios onde ocorreram os 8 surtos de meningoencefalite por herpesvírus bovino-5 descritos neste estudo: 1) São Luiz Gonzaga, 2) Júlio de Castilhos, 3) Cacequi, 4) Manoel Viana, 5) Nova Palma, 6) Tupanciretã, 7) São Vicente do Sul, e 8) Formigueiro. O ponto branco corresponde ao município de Santa Maria. 

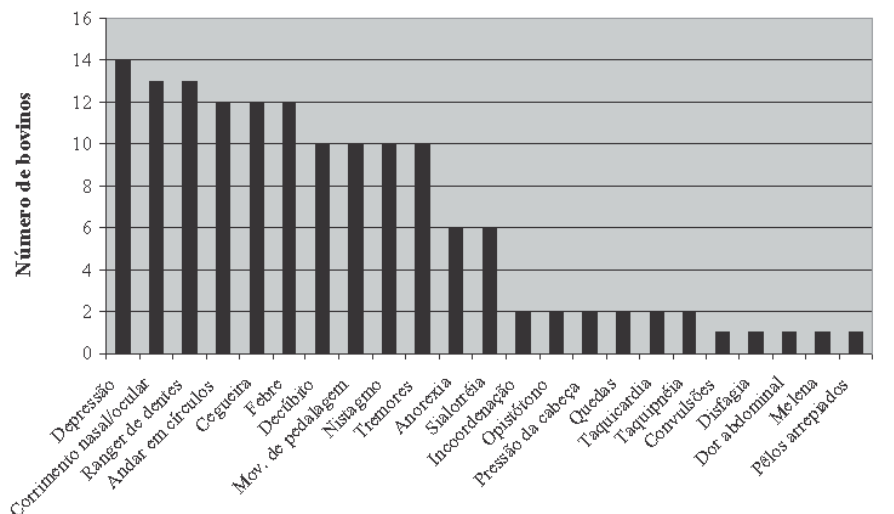

Fig.2. Freqüência dos sinais clínicos em 19 bovinos afetados por meningoencefalite por herpesvírus bovino-5.

examinados foram observados 4 casos sem lesões macroscópicas, 4 casos com lesões circulatórias discretas e 10 casos com lesões circulatórias e degenerativas acentuadas. Em um caso não havia descrição macroscópica. Nos bovinos em que as lesões eram discretas, havia hiperemia dos vasos das leptomeninges por toda a extensão do encéfalo. Lesões moderadas eram caracterizadas por tumefação das porções rostrais do telencéfalo, com achatamento das circunvoluções dos lobos frontais (Fig.5). Nessas áreas havia focos de coloração amarela e consistência mole, característicos de malacia. Com a evolução da doença, essas áreas se tornavam gelatinosas e acinzentadas (Fig.6). Em dois casos foram observadas, além de lesões nos lobos frontais, áreas deprimidas e hemorrágicas no córtex dos lobos parietais do telencéfalo. Nos casos mais avançados uma lesão residual indicava o desaparecimento segmentar do córtex telencefálico (Fig.7), mais acentuado nas porções rostrais (Fig.8). Também foram observadas áreas gelatinosas (malacia) na substância cinzenta dos núcleos basais e do tálamo.

\section{Histopatologia}

Histologicamente todos os bovinos apresentaram meningoencefalite não-supurativa, alguns com malacia, que variou quanto à localização e intensidade nos 19 casos. Os achados foram caracterizados principalmente por alterações circulatórias (hiperemia, hemorragia e edema) distribuídas tanto na neurópila (substância branca, cinzenta ou ambas) quanto nas meninges; alterações inflamatórias, como meningoencefalite nãosupurativa (Fig.9) e, em alguns casos, infiltração difusa de neutrófilos na neurópila (Fig.10). Em 4 casos $(21,05 \%)$ foram observados corpúsculos de inclusão basofílicos intranucleares em astrócitos e neurônios (Fig.11). Em todos os casos foi possível a observação de vários graus de gliose focal ou difusa, caracterizados por hipercelularidade, principalmente da micróglia. Alterações degenerativas foram caracterizadas por necrose neuronal ou neurônio vermelho (Fig.12), neuronofagia (Fig.13) e áreas de malacia infiltradas por células Gitter (Fig.14). Nos ca-

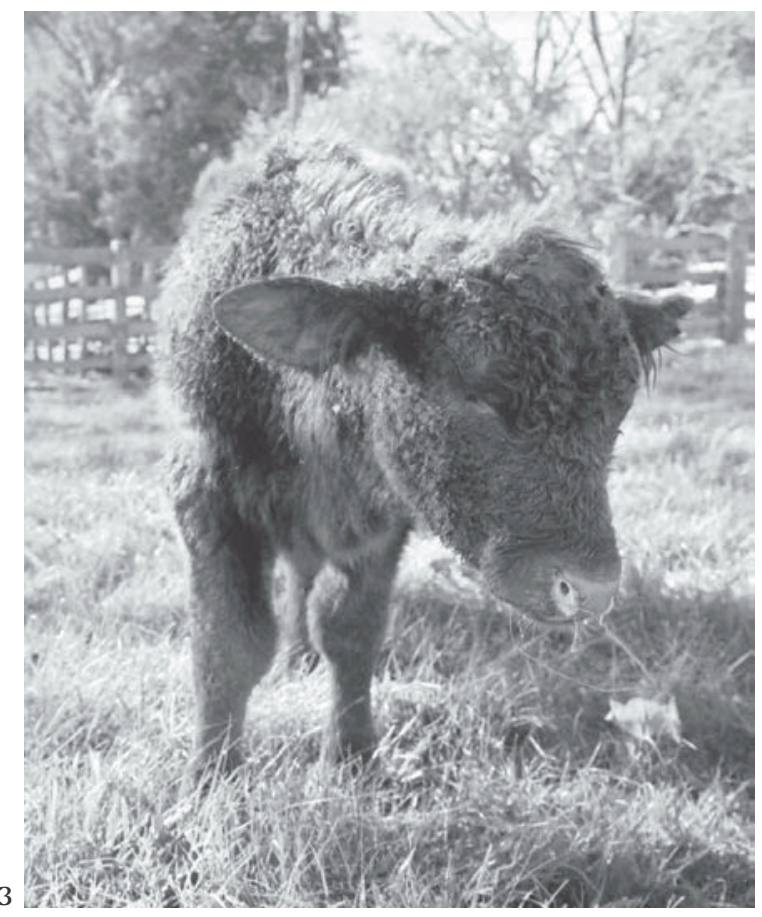

Fig.3. Depressão em bezerro afetado por meningoencefalite por herpesvírus bovino- 5 .

Fig.4. Corrimento nasal em bezerro afetado por meningoencefalite por herpesvírus bovino-5.

Fig.5. A malacia inicia como áreas tumefeitas e marrom-amareladas ou hemorrágicas, no encéfalo. Bezerro afetado por meningoencefalite por herpesvírus bovino-5.
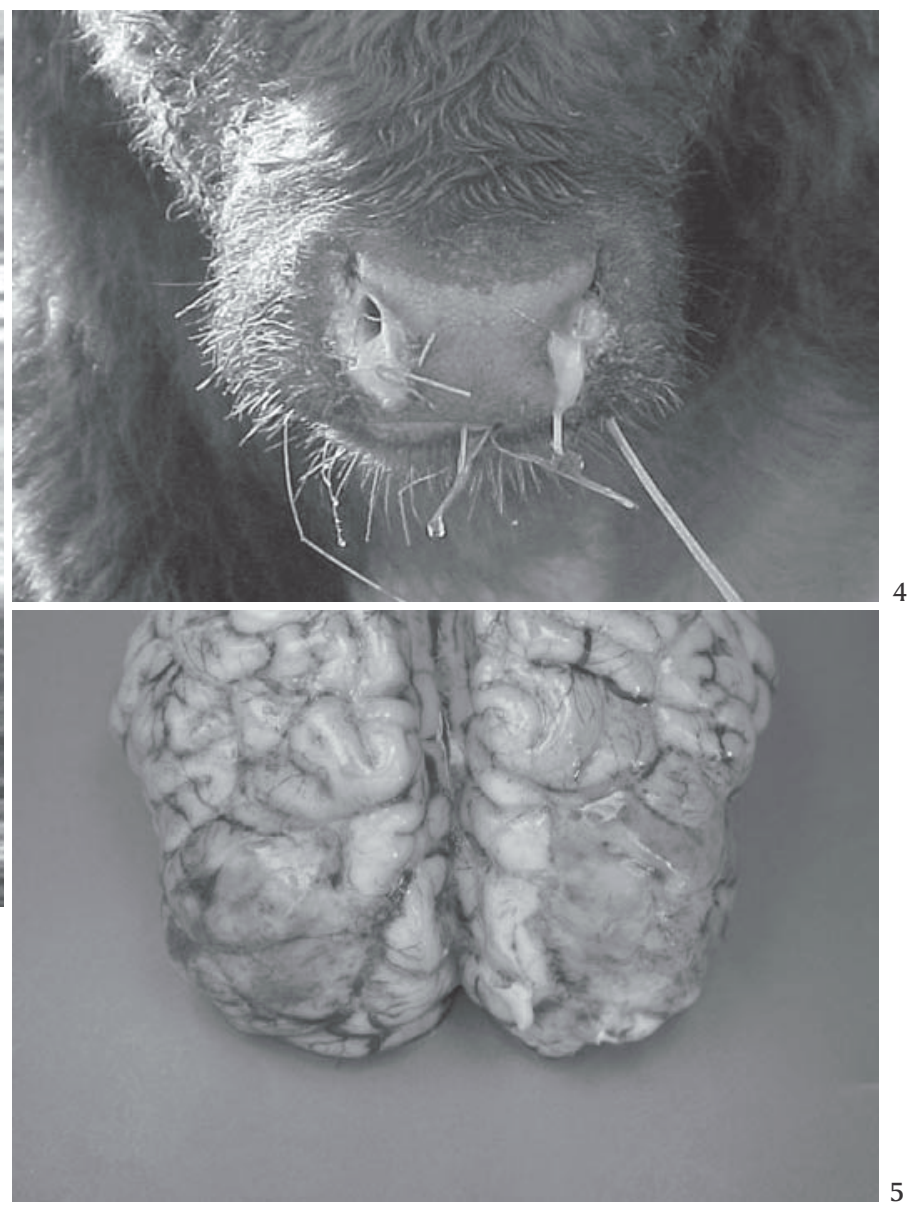

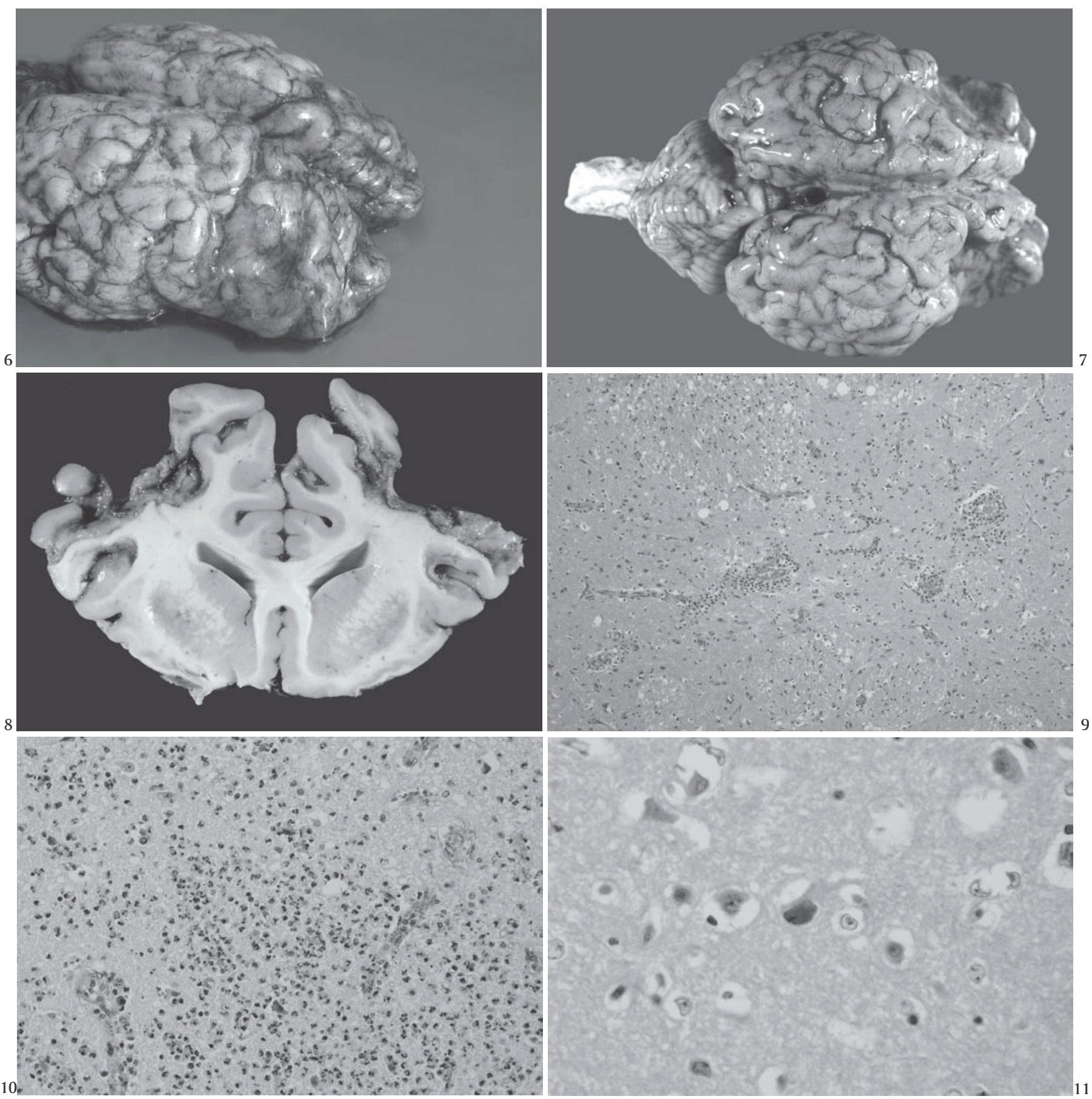

Fig.6. As áreas de malacia se tornam gelatinosas e acinzentadas com a progressão da doença. Encéfalo de bezerro afetado por meningoencefalite por herpesvírus bovino-5.

Fig.8. A superfície de corte evidencia áreas de desaparecimento do córtex telencefálico e áreas gelatinosas nos núcleos basais. Bezerro afetado por meningoencefalite por herpesvírus bovino-5.

Fig.10. Infiltração difusa de neutrófilos na neurópila do encéfalo de bezerro afetado por meningoencefalite por herpesvírus bovino-5. HE, Obj.20.

Fig.7. A lesão residual é caracterizada pelo desaparecimento segmentar do córtex telencefálico, observado pela depressão acentuada nos lobos frontais, no encéfalo de bezerro afetado por meningoencefalite por herpesvírus bovino- 5 .

Fig.9. Células inflamatórias preenchem os espaços perivasculares (espaços de Virchow-Robin) na neurópila do encéfalo de bezerro afetado por meningoencefalite por herpesvírus bovino-5. HE, Obj.10.

Fig.11. Corpúsculo de inclusão basofilico intranuclear em astrócito no encéfalo de bezerro afetado por meningoencefalite por herpesvírus bovino- 5 . HE, Obj. 40 . 

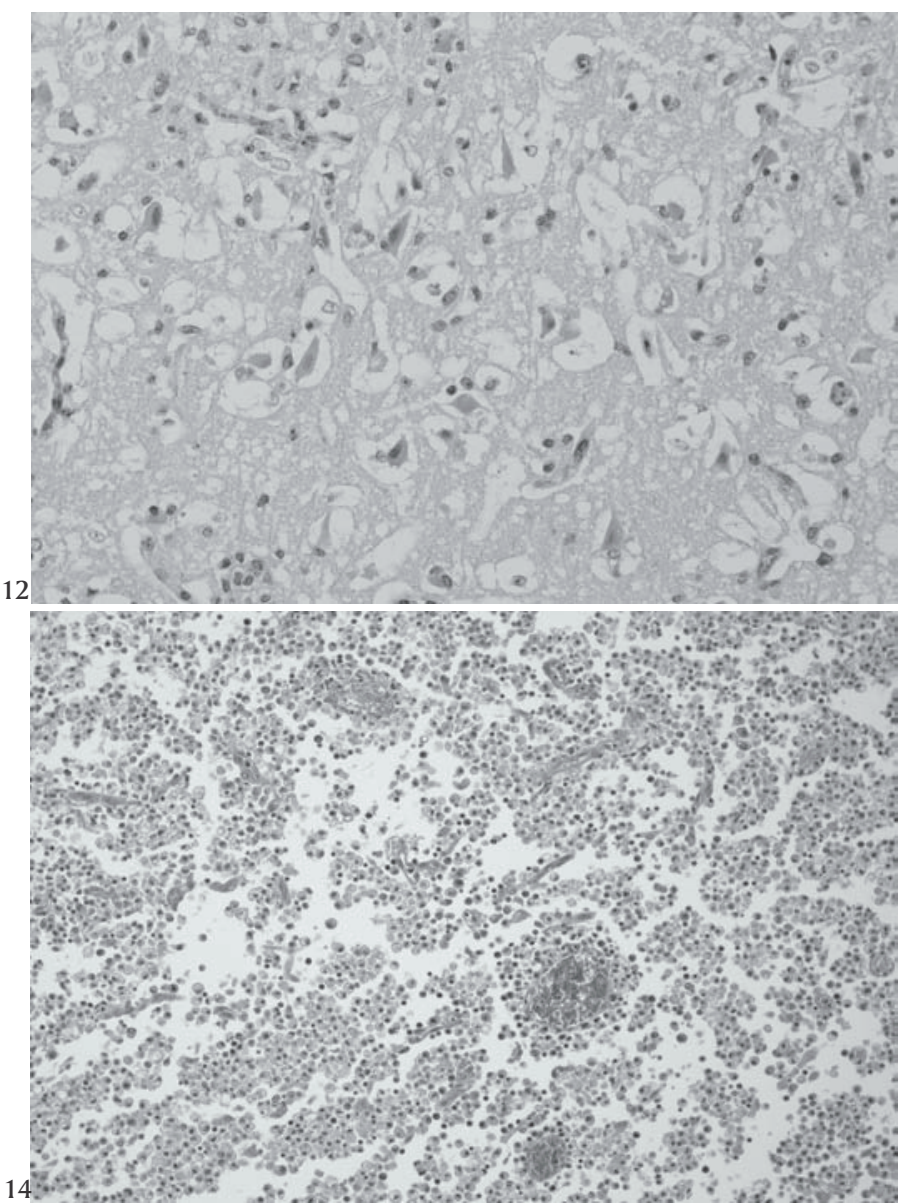

Fig.12. Necrose neuronal aguda no encéfalo de bezerro afetado por meningoencefalite por herpesvírus bovino-5. Os neurônios estão vermelhos, com citoplasma encarquilhado e eosinofílico e têm núcleos picnóticos. HE, Obj.20.

Fig.14. Malacia, caracterizada por necrose do componente neuroectodérmico com manutenção do componente vascular e acentuada infiltração por macrófagos com citoplasma espumoso (células Gitter), no encéfalo de bezerro afetado por meningoencefalite por herpesvírus bovino-5. HE, Obj.10.

sos mais crônicos foram observadas apenas estruturas vasculares e poucas células Gitter, formando uma lesão residual (Fig.15). Não foram encontradas lesões histopatológicas nos gânglios do nervo trigêmeo examinados, exceto por um leve aumento na quantidade de células gliais perineuronais em algumas seções. A intensidade dessas lesões foi mais acentuada, em ordem decrescente, na região cortical dos lobos frontais do telencéfalo, na cápsula interna e núcleos da base, no tálamo, no tronco encefálico, no córtex parietal, córtex occipital e cerebelo. 0 tipo, a intensidade e a distribuição histológica das lesões encontradas em 19 bovinos necropsiados neste estudo encontram-se nas Figuras 16-18.

\section{DISCUSSÃO}

O diagnóstico de meningoencefalite por BoHV-5 foi realizado a partir dos dados epidemiológicos, sinais clínicos, achados de
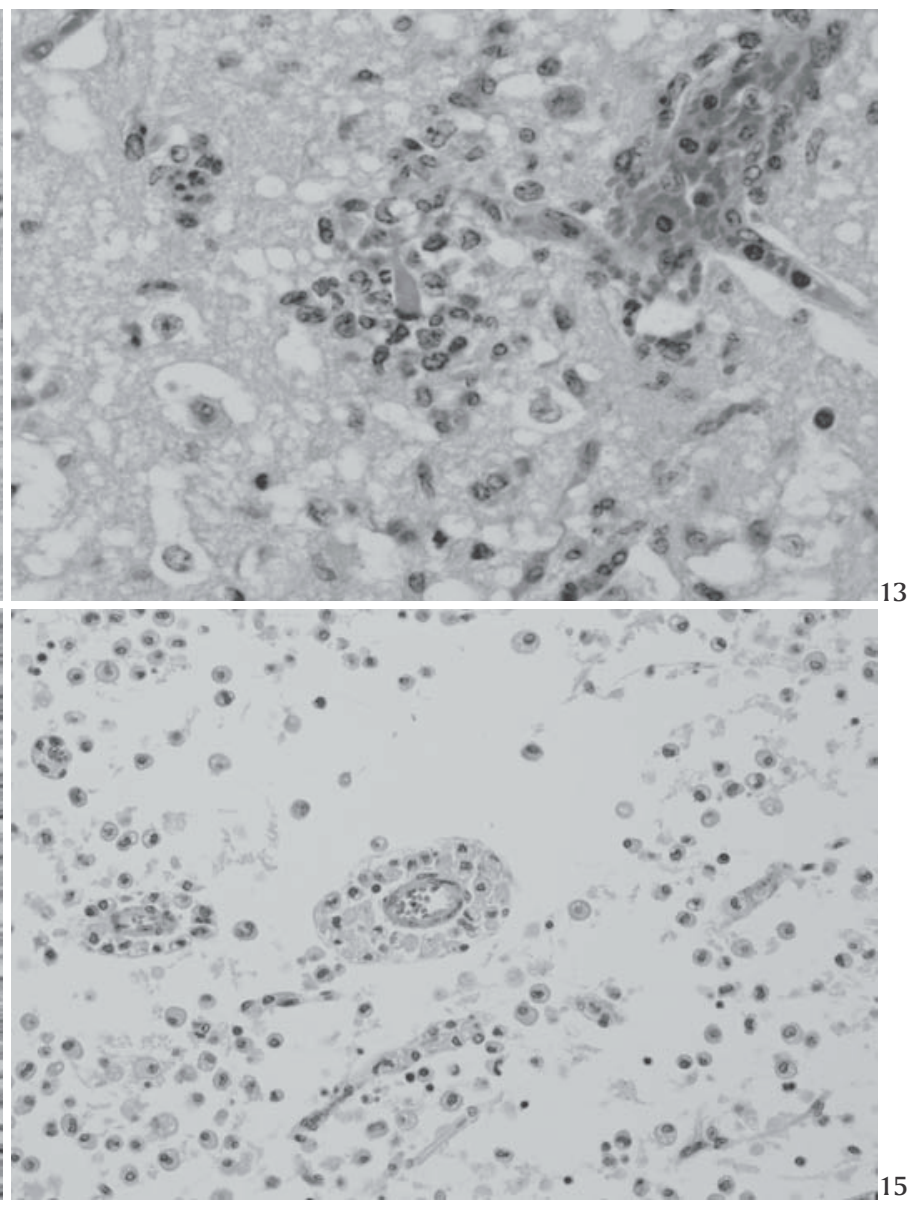

Fig.13. Encéfalo de bezerro afetado por meningoencefalite por herpesvírus bovino-5. Neuronofagia. HE, Obj.40.

Fig.15. Encéfalo de bezerro afetado por meningoencefalite por herpesvírus bovino-5. Há desaparecimento do tecido cortical normal, permanecendo apenas células Gitter e vasos. HE, Obj.10.

necropsia e histopatológicos característicos e a confirmação pela detecção viral em cultivo celular, imunofluorescência ou PCR. Em 3 surtos, perfazendo 14 bovinos afetados, a confirmação do diagnóstico foi realizada por inoculação em cultivo celular, imunofluorescência e PCR. Embora a PCR seja, dentre essas técnicas, o único método que confirma BoHV-5, o cultivo celular e a imunofluorescência permitem que o diagnóstico presuntivo de infeção por BoHV-5 seja determinado com base nos dados epidemiológicos e lesões histopatológicas, já que são raros os casos de meningoencefalite por BoHV-1 (Roels et al. 2000, Penny et al. 2002). Em 4 surtos não foi enviado material para exames virológicos e em outro a inoculação em cultivo celular resultou negativa. Nesses casos o diagnóstico de meningoencefalite por herpesvírus foi feito com base na epidemiologia, nos sinais clínicos e, principalmente, na histopatologia, que foram idênticos aos observados nos outros casos confirmados. 


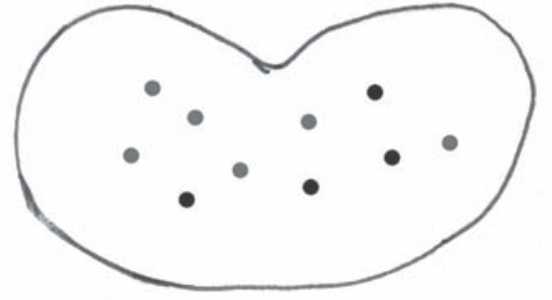

A

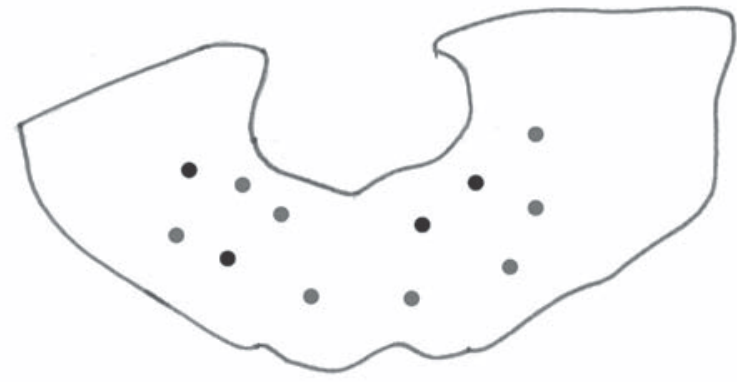

$\mathrm{B}$

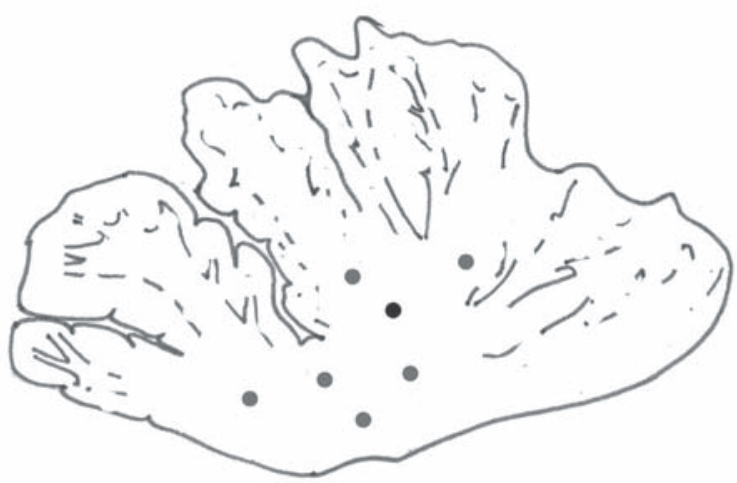

$\mathrm{C}$

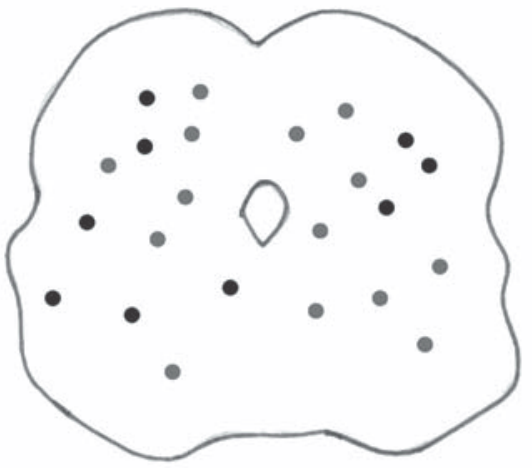

$\mathrm{D}$
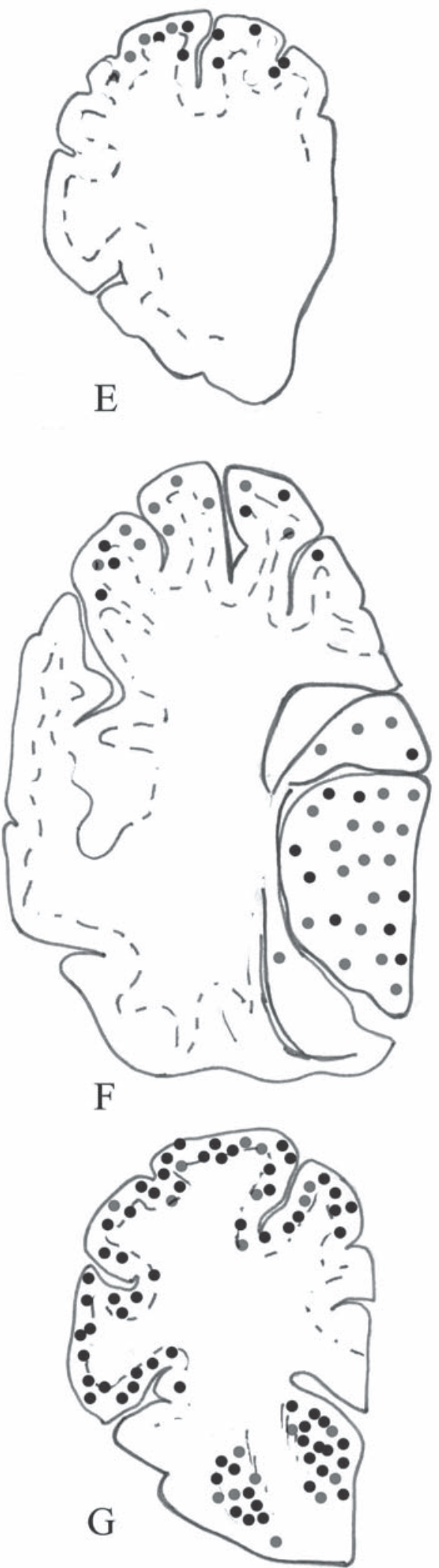

Fig.16. Distribuição das alterações histopatológicas no encéfalo de 19 bovinos afetados pela meningoencefalite por herpesvírus bovino tipo-5. Os pontos escuros correspondem às áreas de inflamação e degeneração. A) Bulbo na altura do óbex; B) ponte com pedúnculos cerebelares; C) cerebelo; D) mesencéfalo na altura dos colículos rostrais; E) córtex occipital; F) córtex parietal, hipocampo e tálamo; e G) córtex frontal na altura do joelho do corpo caloso e dos núcleos basais. 


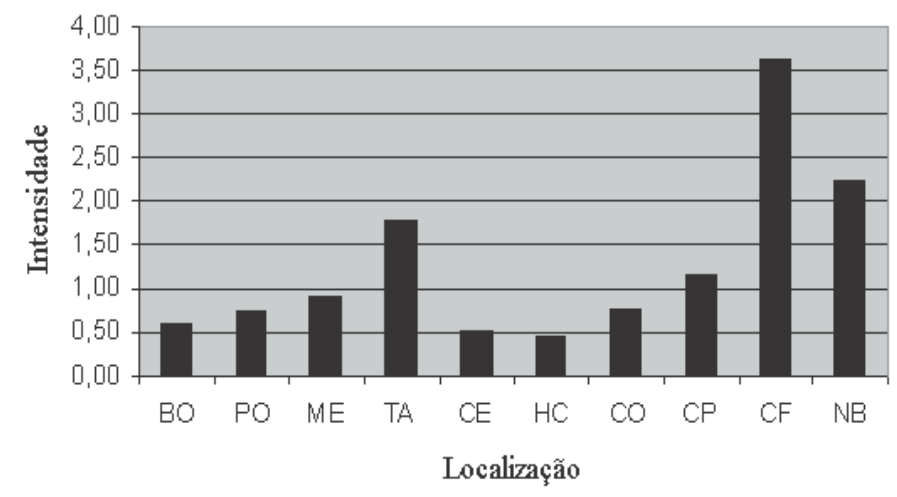

Fig.17. Distribuição e intensidade de três alterações histopatológicas (inflamação, neurônios vermelhos e malacia) no encéfalo de 19 bovinos afetados pela enfermidade. $\mathrm{BO}$, bulbo na altura do óbex; $\mathrm{PO}$, ponte; ME, mesencéfalo; TA, tálamo; $\mathrm{CE}$, cerebelo; $\mathrm{HC}$, hipocampo; $\mathrm{CO}$, córtex occipital; $\mathrm{CP}$, córtex parietal; $\mathrm{CP}$, córtex frontal; NB, núcleos basais.

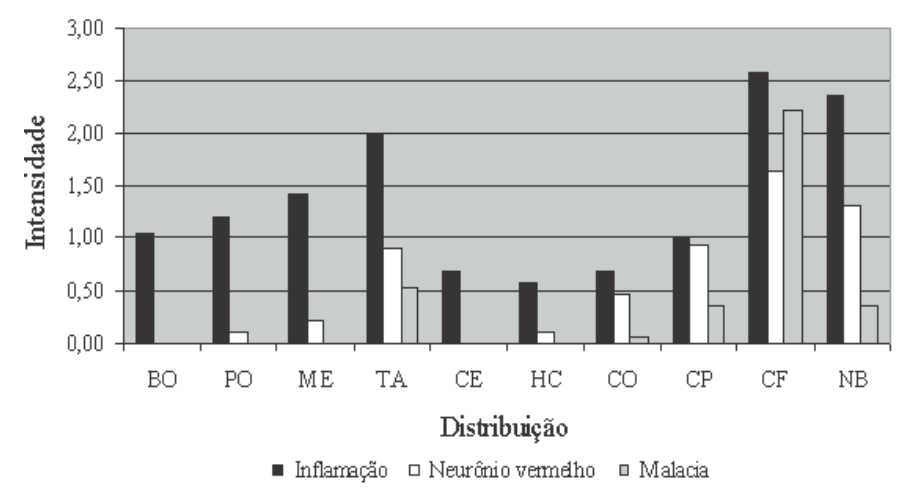

Fig.18. Distribuição e intensidade da soma de todas as alterações histopatológicas (hemorragia, edema da neurópila, tumefação das células endoteliais, infiltrado inflamatório, meningite, gliose focal, gliose difusa, neurônios vermelhos, neuronofagia, malacia e lesão residual) no encéfalo dos 19 bovinos afetados por meningoencefalite por herpesvírus bovino-5. BO, bulbo na altura do óbex; PO, ponte; ME, mesencéfalo; TA, tálamo; $\mathrm{CE}$, cerebelo; $\mathrm{HC}$, hipocampo; $\mathrm{CO}$, córtex occipital; $\mathrm{CP}$, córtex parietal; $\mathrm{CP}$, córtex frontal; NB, núcleos basais.

Nos casos de meningoencefalite por BoHV-5 acompanhados neste estudo, envolvendo um total de 1.359 bovinos sob risco, os coeficientes gerais de morbidade, mortalidade e letalidade foram de $3,97 \%, 3,67 \%$ e $92,59 \%$, respectivamente, e são semelhantes aos descritos em diversos relatos da enfermidade (Johnston et al. 1962, Barenfus et al. 1963, Gardiner et al. 1964, Bartha et al. 1969, Carrillo et al. 1983a,b, Salvador et al. 1998, Colodel et al. 2002, Elias et al. 2004). Os surtos ocorreram em várias regiões do Estado, sem concentração em qualquer época do ano, e afetaram bovinos entre 1-18 meses de idade, sem preferência por raça ou sexo.

A relação entre surtos meningoencefalite por BoHV-5 e situações de estresse é bem conhecida (Engels \& Ackermann 1996) e o desmame é um fator de risco importante para o desenvolvimento da doença (Gardiner et al. 1964, George 1991, Elias et al. 2004). Em 6 das 8 propriedades (75\%) deste estudo os bovinos haviam sido desmamados em um período de aproximadamente 20-120 dias antes do início da doença. Outros fatores de estresse também foram observados nos rebanhos afetados e incluíam mudanças no manejo alimentar e separação dos bezerros das vacas adultas durante determinados períodos do dia. Em uma oportunidade não foi possível detectar qualquer fator de estresse. Na época do desmame, há diminuição nos níveis dos anticorpos da imunidade passiva (George 1991). O pico de absorção de anticorpos maternos ocorre em torno de 12-24 horas após o nascimento (Radostits et al. 2002) e começa a baixar quando o bezerro atinge aproximadamente 10 semanas (George 1991), permanecendo, no entanto, até os seis meses de idade (Radostits et al. 2002). Em um estudo (Belknap et al. 1994), bezerros que ingeriram o colostro não desenvolveram a doença clínica após inoculação intranasal com uma amostra de BoHV-5. Entretanto, esses animais eliminaram o vírus após administração de dexametasona, 60 dias pósinoculação Esses achados demonstraram que bovinos que adquirem imunidade à doença podem atuar como reservatórios do vírus, que permanece latente até ser reativado e eliminado para o restante do rebanho. Essa reativação viral pode ser acompanhada de doença clínica, embora ruminantes freqüentemente desenvolvam reativação subclínica (Engels \& Ackermann 1996). Esses achados fortalecem a hipótese de que o desmame elevaria os níveis de corticosteróides endógenos liberados pelo córtex adrenal em resposta ao estresse, num momento em que os anticorpos da imunidade passiva estão baixando.

Em 5 propriedades onde ocorreram os casos da enfermidade, os bezerros eram aglomerados em algum momento do dia para receber alimentação em cocho comum, o que permitia o contato íntimo entre eles. $O$ contato entre bovinos suscetíveis e infectados é um fator importante na disseminação do vírus em um rebanho (Barenfus et al. 1963, Bartha et al. 1969, Engels \& Ackermann 1996). $O$ agente é transmitido por meio de aerossóis, por contato íntimo, pela água ou por alimento contaminado e potenciais portas de entrada para o vírus incluem a cavidade nasal, orofaringe e mucosa ocular, onde ocorre invasão das terminações nervosas e subseqüiente invasão do SNC ou gânglios sensoriais. Nos gânglios, o vírus pode assumir latência (Engels \& Ackermann 1996). O bulbo olfatório tem sido demonstrado como uma rota eficiente na infecção experimental por BoHV-5 em coelhos (Beltrão et al. 2000, Diel et al. 2005) e, a julgar pela distribuição das lesões, essa foi a via de entrada do vírus nos bovinos afetados neste estudo.

Lesões macroscópicas foram observadas em 14 casos e consistiam de variados graus de hiperemia dos vasos das leptomeninges e malacia, principalmente nas porções rostrais do telencéfalo. A malacia é descrita como um achado freqüente nos encéfalos de bovinos afetados por meningoencefalite por BoHV5 no Canadá, Uruguai, Argentina e Brasil (Beck 1975, Gough \& James 1975, Dias et al. 1982, Carrillo et al. 1983a,b, Salvador et al. 1998, Colodel et al. 2002, Elias et al. 2004). Esse é um ponto em que os casos de meningoencefalite por BoHV-5 descritos no Brasil, Uruguai e Argentina diferem dos casos descritos na Austrália e em outros países da Europa e América do Norte (Barenfus et al. 1963, Gardiner et al. 1964, Bartha et al. 1969, McKercker et 
al. 1970, Bagust 1972, Bagust \& Clark 1972, Reed et al. 1973, Watt et al. 1981), nos quais não é descrita a presença dessa alteração.

Os achados morfológicos descritos nos encéfalos de bovinos afetados por BoHV-5 neste estudo são importantes no diagnóstico diferencial de outras encefalites virais de bovinos no Brasil e incluem raiva, febre catarral maligna (Sanches et al. 2000) e, menos freqüentemente, doença de Aujeszky (Bauer 1965, Néspoli et al. 2003). Embora todas essas doenças cursem com encefalite não-supurativa, as áreas de malacia cortical (muitas vezes visíveis macroscopicamente) nas regiões frontais do encéfalo são aspectos distintivos da meningoencefalite por BoHV5.

É sugerido que o achado de corpúsculos de inclusão intranucleares $(\mathrm{Cl})$ é definitivo para o diagnóstico histopatológico de meningoencefalite por BoHV-5 (Elias et al. 2004) e muitos autores têm encontrado esses $\mathrm{CI}$ numa proporção que varia de $85,7 \%$ (Salvador et al. 1998) a $100 \%$ (Elias et al. 2004) dos casos. Por outro lado, outros autores descrevem o achado de CI como raro (George 1991) ou ausente (Barenfus et al. 1963). Neste estudo os $\mathrm{CI}$ foram observados em apenas $21,05 \%$ dos casos examinados. Alguns autores relatam que a presença de CI é mais freqüente em materiais bem conservados (Summers et al. 1995). É possível que esse fator tenha influenciado os resultados referentes a esse achado, já que muitos dos encéfalos foram enviados refrigerados por veterinários de campo e demoraram algum tempo até serem fixados em formol. Em razão disso consideramos pouco confiável a consideração da presença ou não de $\mathrm{CI}$ para confirmação ou eliminação do diagnóstico de meningoencefalite por BoHV-5. Vasculite é outro achado histopatológico descrito por alguns autores (Colodel et al. 2002) e que não pudemos confirmar em nossos casos.

Os achados histopatológicos relacionados à malacia foram semelhantes aos descritos em relatos da enfermidade no Brasil. É aceito que estágios bem desenvolvidos de malacia ocorram por volta de duas semanas ou mais após o insulto (Innes \& Saunders 1962, Storts 1998). No entanto, malacia tem sido descrita após dois ou três dias de evolução clínica na infecção por BoHV-5 (Salvador et al. 1998, Elias et al. 2004) e tem sido relacionada, por alguns autores, com o período de evolução da doença (Salvador et al. 1998). Isso demonstra que essa alteração pode se desenvolver em menor período de tempo, nessa e em outras doenças, como já foi observado (Oliveira et al. 2005).

A maioria dos relatos de surtos espontâneos de meningoencefalite por BoHV-5 não mencionam achados histopatológicos no gânglio do nervo trigêmeo (GT) ou gânglio de Gasser (Johnston et al. 1962, Barenfus et al. 1963, Gardiner et al. 1964, Carrillo et al. 1983a,b, Riet-Correa et al. 1989, Salvador et al. 1998, Colodel et al. 2002, Elias et al. 2004). Entretanto, alguns experimentos realizados com bovinos relatam a ocorrência de discreta ganglioneurite envolvendo o GT e o nervo trigêmeo (Meyer et al. 2001, Perez et al. 2002). Nos casos deste estudo não se observou qualquer tipo de alteração histopatológica nos gânglios de Gasser. Acúmulos discretos de células mononucleares e proliferação das células satélites dos neurônios do GT são encontrados em bovinos normais examinados durante o diagnóstico de rotina (Rech et al. 2006). Talvez a ausência de lesões no GT em nossos casos possa estar relacionada à via de infecção que parece ter sido por via olfatória e não pelos pares de nervos cranianos.

\section{REFERÊNCIAS}

Bagust T.J. 1972. Comparison of the biological, biophysical and antigenic properties of four strains of infectious bovine rhinotracheitis herpesvirus. J. Comp. Pathol. 82:365-374.

Bagust T.J. \& Clark L. 1972. Pathogenesis of meningoencephalitis produced in calves by infectious bovine rhinotracheitis herpesvirus. J. Comp. Pathol. 82:375-383.

Barenfus M., Delli Quadri C.A., McIntyre R.W. \& Schroeder R.J. 1963. Isolation of infectious bovine rhinotracheitis virus from calves with meningoencephalitis. J. Am. Vet. Med. Assoc. 143:725-728.

Barros C.S.L. \& Marques G.H.F. 2003. Procedimentos para o diagnóstico das doenças do sistema nervoso central de bovinos. Depto Defesa Animal, Ministério da Agricultura, Pecuária e Abastecimento (MAPA), Brasília. 50p. Disponível na internet: http://www.agricultura.gov.br

Bartha A., Hadju G., Áldásy P. \& Paczolay G. 1969. Occurrence of encephalitis caused by infectious bovine rhinotracheitis virus in calves in Hungary. Acta Vet. Acad. Scient. Hung. 19:145-151.

Bauer A.G. 1965. Primeira constatação do mal de Aujeszky no R. G. do Sul. Arqs Inst. Pesq. Vet. Desidério Finamor, Porto Alegre, 1:15-16.

Beck B.E. 1975. Infectious bovine rhinotracheitis encephalomyelitis in cattle and its differential diagnosis. Can. Vet. J. 16:269-271.

Belknap E.B., Collins J.K., Ayers V.K. \& Schultheiss P.C. 1994. Experimental infection of neonatal calves with neurovirulent bovine herpesvirus type 1.3. Vet. Pathol. 31:358-365.

Beltrão N., Flores E.F., Weiblen R., Silva A.M., Roehe P.M. \& Irigoyen L.F. 2000. Infecção e enfermidade neurológica pelo herpesvírus bovino tipo 5 (BHV-5): coelhos como modelo experimental. Pesq. Vet. Bras. 20:144150 .

Carrillo B.J., Ambrogí A., Schudel A.A., Vazquez M., Dahme E. \& Pospischil A. 1983a. Meningoencephalitis caused by IBR virus in calves in Argentina. Zentralbl. Veterinaermed. Reihe B 30:327-332.

Carrillo B.J., Pospischil A. \& Dahme E. 1983b. Pathology of a bovine necrotizing encephalitis in Argentina. Zentralbl. Veterinaermed. Reihe B 30:161-168.

Colodel E.M., Nakazato L., Weiblen R., Mello R.M., Silva R.R.P., Souza M.A., Filho J.A.O. \& Caron L. 2002. Meningoencefalite necrosante em bovinos causada por herpesvírus bovino no estado de Mato Groso do Sul, Brasil. Ciência Rural, Santa Maria, 32:293-298.

Diel D.G., Fonseca E.T., Souza S.F., Mazzanti A., Bauermann F., Weiblen R. \& Flores E.F. 2005. O herpesvírus bovino tipo 5 (BoHV-5) pode utilizar as rotas olfatória ou trigeminal para invadir o sistema nervoso central de coelhos, dependendo da via de inoculação. Pesq. Vet. Bras. 25:164-170.

Dias L.E., Maisonnave J., Guarino H., Paullier C., Perdomo E., Figares A. \& Izaguirre R. 1982. Rinotraqueitis infecciosa bovina (IBR): descripcion de um cuadro clinico em terneros de tambo. In: $3^{\circ}$ Congr. Nac. Vet., Montevideo, p.521-530.

Elias F., Schild A.L. \& Riet-Correa F. 2004. Meningoencefalite e encefalomalacia por herpesvírus bovino-5: distribuição das lesões no sistema nervoso central de bovinos naturalmente infectados. Pesq. Vet. Bras. 24:123-131.

Engels M. \& Ackermann M. 1996. Pathogenesis of ruminant herpesvirus infections. Vet. Microbiol. 53:3-15.

Gardiner M. R., Nairn M.E. \& Sier M. 1964. Viral meningoencephalitis of calves in Western Australia. Aust. Vet. J. 40:225-228.

George L.W. 1991. Understanding the encephalitic form of infectious bovine rhinotracheitis. Vet. Med. 335-337.

Gough A. \& James D. 1975. Isolation of IBR virus from a heifer with meningoencephalitis. Vet. Journal 16:313-314. 
Innes J.R.M. \& Saunders L.Z. 1962. Encephalomalacia and Myelomalacia, p.607-624. In: Ibid. (ed.) Comparative Neuropathology. Academic Press, New York. 837p.

Johnston L.A.Y., Simmons G.C. \& McGavin M.D. 1962. Viral meningoencephalitis in calves. Aust. Vet. J. 38:207-215.

McKercher D.G., Bibrack B. \& Richards W.P.C. 1970. Effects of the infectious bovine rhinotracheitis virus on the central nervous system of cattle. J. Am. Vet. Med. Assoc. 156:1460-1467.

Meyer G., Lemaire M., Ros C., Belak K., Gabriel A., Cassart D., Coignoul F., Belak S. \& Thiry E. 2001. Comparative pathogenesis of acute and latent infections of calves with bovine herpesvirus types 1 and 5. Arch. Virol. 146:633-652

Néspoli J.B., Néspoli P.B., Colodel E.M., Lima D.A., Moura Estevão P.C.N. \& Gonçalves J.A. 2003. Surto de pseudo-raiva (doença de Aujeszky) bovina no Estado do Mato Grosso. 5 Congr. Bras. Buiatria, Salvador, p. 45. (Resumo)

Oliveira F.N., Rech R.R., Rissi D.R., Barros R.R. \& Barros C.S.L. 2005. Intoxicação em suínos pela ingestão de sementes de Aeschynomene indica. Pesq. Vet. Bras. 25:135-142.

Penny C.D., Howie F., Nettleton P.F. \& Schock A. 2002. Upper respiratory disease and encephalitis in neonatal beef calves caused by bovine herpesvirus type 1. Vet. Rec. 151:89-91.

Perez S.E., Bretschneider G., Leunda M.R., Osorio E.A., Flores E.F. \& Odeon A.C. 2002. Primary infection, latency, and reactivation of bovine herpesvirus type 5 in bovine nervous system. Vet. Pathol. 39:437-444.

Radostits O.M., Gay C.C., Blood D.C. \& Hinchcliff K.W. 2002. Doenças virais caracterizadas por sinais nervosos, p.1069-1113. In: Ibid. (ed.) Clínica Veterinária: Um Tratado de Doenças dos Bovinos, Ovinos, Suínos, Caprinos

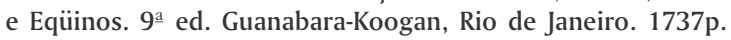

Rech R.R, Rissi D.R., Silva M.C., Inkelmann M.A. \& Barros C.S.L. 2006. Histomorfologia do gânglio de Gasser, da rete mirabile carotídea e da hipófise de bovinos: estudo de 199 casos. Pesq. Vet. Bras. 26(2):105111.

Reed D.E., Bicknell E.J. \& Bury R.J. 1973. Systemic form of infectious bovine rhinotracheitis in young calves. J. Am. Vet. Med. Assoc. 156:753755 .

Riet-Correa F., Vidor T., Schild A.L. \& Méndez M.C. 1989. Meningoencefalite e necrose do córtex cerebral em bovinos por Herpesvírus bovino-1. Pesq. Vet. Bras. 9:13-16.

Roels S., Charlier G., Letellier C., Meyer G., Schynts F., Kerkhofs P., Thiry E. \& Vanopdenbosch E. 2000. Natural case of bovine herpesvirus 1 meningoencephalitis in an adult cow. Vet. Rec. 146:586-588.

Salvador S.W.C., Lemos R.A.A., Riet-Correa F., Roehe P.M. \& Osório A.L.A.R. 1998. Meningoencefalite em bovinos causada por herpesvírus bovino-5 no Mato Grosso do Sul e São Paulo. Pesq. Vet. Bras. 18:76-83.

Sanches A.W.D., Langohr I.M., Stigger A.L. \& Barros C.S.L. 2000. Doenças do sistema nervoso central em bovinos no Sul do Brasil. Pesq. Vet. Bras. 20:113-118

Storts R.W. 1998. O sistema nervoso, p.353-416. In: McGavin M.D. \& Carlton W.W. (ed.) Patologia Especial de Thomson. 2 ${ }^{\underline{a}}$ ed. ArtMed, Porto Alegre. 672p.

Summers B.A., Cummings, J.F. \& de Lahunta A. 1995. Inflammatory diseases of the central nervous system. p. 95-188. In: Ibid (ed.) Veterinary Neuropathology. Mosby, Saint Louis. 527p.

Watt J.A., Johnston W.S., Macleod N.S. \& Barlow R.M. 1981. Infectious bovine rhinotracheitis and encephalitis. Vet. Rec. 108:63-64.

Weiblen R., Barros C.S.L., Canabarro T.F. \& Flores E.F. 1989. Bovine meningoencephalitis from IBR virus. Vet. Rec. 124:666-667. 